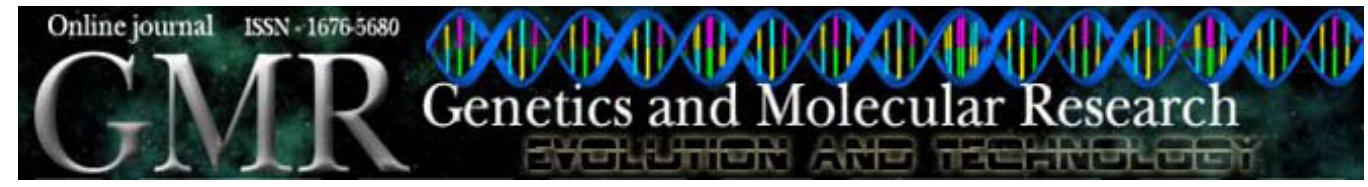

\title{
Variable number of tandem repeat markers in the genome sequence of Mycosphaerella fijiensis, the causal agent of black leaf streak disease of banana (Musa spp)
}

\author{
S.A.L. Garcia ${ }^{1 *}$, T.A.J. Van der Lee ${ }^{1 *}$, C.F. Ferreira ${ }^{12^{2 *}}$, B. Te Lintel Hekkert', \\ M.-F. Zapater ${ }^{3}$, S.B. Goodwin ${ }^{4}$, M. Guzmán ${ }^{5}$, G.H.J. Kema ${ }^{1}$ and M.T. Souza Jr. ${ }^{1,6}$ \\ ${ }^{1}$ Plant Research International B.V., Wageningen University and Research Centre, \\ Wageningen, The Netherlands \\ ${ }^{2}$ Embrapa Mandioca e Fruticultura, Cruz das Almas, BA, Brasil \\ ${ }^{3}$ Biologie et Génétique des Interactions Plantes-Parasites, CIRAD-INRA-AGRO.M, \\ Montpellier, France \\ ${ }^{4}$ USDA-ARS, Crop Production and Pest Control Research Unit, West Lafayette, IN, USA \\ ${ }^{5}$ CORBANA, La Rita, Limón, Costa Rica \\ ${ }^{6}$ Embrapa Agroenergia, Brasília, DF, Brasil \\ *These authors contributed equally to this study. \\ Corresponding author: M.T. Souza Jr. \\ E-mail:manoel.souza@embrapa.br
}

Genet. Mol. Res. 9 (4): 2207-2212 (2010)

Received July 25, 2010

Accepted September 8, 2010

Published November 9, 2010

DOI 10.4238/vol9-4gmr934

\begin{abstract}
We searched the genome of Mycosphaerella fijiensis for molecular markers that would allow population genetics analysis of this plant pathogen. M. fijiensis, the causal agent of banana leaf streak disease, also known as black Sigatoka, is the most devastating pathogen attacking bananas (Musa spp). Recently, the entire genome sequence of $M$. fijiensis became available. We screened this database for VNTR markers. Forty-two primer pairs were selected for validation, based on repeat type and length and the number of repeat units. Five VNTR markers showing multiple alleles were validated with a reference set of isolates from different parts of the world and a population from a banana plantation in Costa Rica. Polymorphism information content values varied from 0.6414 to 0.7544 for the reference set and from 0.0400 and 0.7373 for the population set. Eighty percent of the polymorphism information content
\end{abstract}


values were above 0.60 , indicating that the markers are highly informative. These markers allowed robust scoring of agarose gels and proved to be useful for variability and population genetics studies. In conclusion, the strategy we developed to identify and validate VNTR markers is an efficient means to incorporate markers that can be used for fungicide resistance management and to develop breeding strategies to control banana black leaf streak disease. This is the first report of VNTR-minisatellites from the M. fijiensis genome sequence.

Key words: Molecular markers; VNTRs; Genetic diversity; Population genetics; Black Sigatoka

\section{INTRODUCTION}

Banana leaf streak disease (also known as black Sigatoka), caused by the heterothallic fungus Mycosphaerella fijiensis, is the most devastating disease affecting bananas (Musa spp) (Marin et al., 2003; Cordeiro et al., 2004; Conde et al., 2007). In humid, high rainfall areas, even well-managed plantations are sprayed with fungicides every week throughout the year, in order to control this disease (Mourichon et al., 1997). These inputs often represent a considerable percentage of total production costs and add-up to hundreds of millions of US dollars per year for the global banana industry.

Black Sigatoka was originally identified in Fiji in 1963 (Rhodes, 1964) and nowadays it is present in most important banana growing areas worldwide (Arzanlou et al., 2007). $M$. fijiensis is a heterothallic ascomycete, which is haploid for the vegetative part of its lifecycle. The sexual cycle results in air-borne ascospores that play an important role in the epidemiology of this disease. After disposition, germ tubes of ascospore or asexual conidia penetrate the stomata. Subsequently, during the biotrophic phase, filamentous hyphae grow slowly and intercellularly in the mesophyll. This is followed by a necrotrophic phase, resulting in abundant cell death that turns the leaves fully necrotic. As a result, $M$. fijiensis decreases photosynthesis, reduces fruit size and induces early maturation in susceptible banana cultivars. M. fijiensis is related to the Sigatoka pathogen M. musicola but is more aggressive and hence, it is globally replacing that pathogen even at higher altitudes (Arzanlou et al., 2007).

Although molecular markers have been developed for use in banana improvement, focusing on germplasm characterization and identification of A and B genomes (Lagoda et al., 1998; Creste et al., 2005; Buhariwalla et al., 2005), little has been devoted to the development of DNA markers for important banana pathogens such as M. fijiensis (Molina and Kahl, 2004).

The objective of the current study is to present a set of variable number of tandem repeat markers (VNTRs) that were identified in the M. fijiensis genome sequence. VNTRs are multiallelic loci that consist of repeated core sequences ( $>6$ nucleotides), also known as minisatellites, tandemly repeated and flanked by segments of non-repetitive sequences, allowing the VNTR blocks to be extracted with restriction enzymes and analyzed by restriction fragment length polymorphism, or amplified by polymerase chain reaction (PCR) and their size determined by gel electrophoresis. The versatility and efficiency of these markers in genotyping and diversity studies were tested on both laboratory strains and field isolates of $M$. fijiensis.

\section{MATERIAL AND METHODS}

In 2007, a 7.1X equivalent of the estimated 73.4 Mbp M. fijiensis (isolate CIRAD086) 
genome (http://genome.jgi-psf.org/Mycfi1/Mycfil.home.html) was produced at the Joint Genome Institute of the United States Department of Energy (http://www.jgi.doe.gov/). The consensus sequences of this genome were submitted to analysis in a bioinformatics pipeline for VNTR detection, which consists of a primer development module. This pipeline chops genomic sequences into 1500-bp size fragments with a 100-bp overlap, then detects VNTRs using a Perl script allowing imperfect repeat VNTR detection by using the scan-for-matches program (Dsouza et al., 1997), and finally generates a maximum of five primer sets by using Primer3 (Rozen and Skaletsky, 2000) that could then amplify a VNTR by PCR followed by screening for unique primer pairs. Additional optimization of the primer pairs was performed using the Fast PCR Professional 5.2 software (http://www.biocenter.helsinki.fi/bi/programs/ fastpcr.htm).

The initial screening for polymorphism was carried out using a reference set of eight M. fijiensis isolates: CIRAD086 (Cameroon, mat1-1), CIRAD139a (Colombia, mat1-2), CBS845 (Indonesia), CBS846 (Philippines), CBS848 (New Caledonia), CBS849 (Burundi), CBS851 (Gabon), and CBS852 (Tanzania) from the Fungal Diversity Centre (http://www.cbs. knaw.nl/) in The Netherlands. The validation and versatility with the emphasis on differentiation and allele size stability were assessed on a population of M. fijiensis isolates (48 individuals), obtained from single ascospore cultures, that had been collected in the San Pablo banana plantation in Costa Rica. Total DNA was isolated from $30 \mathrm{mg}$ mycelium using the Wizard ${ }^{\mathbb{R}}$ Magnetic DNA Purification System for food (PROMEGA food kit, Wisconsin, USA), following manufacturer instructions, resuspended in $100 \mu \mathrm{L}$ nuclease-free water, and stored at $-20^{\circ} \mathrm{C}$ until use. VNTR markers were amplified in a $20 \mu \mathrm{L}-\mathrm{PCR}$ aliquot consisting of: $1 \mathrm{X}$ reaction buffer [10 mM Tris-HCl, pH 9.0, $1.5 \mathrm{mM} \mathrm{MgCl}, 50 \mathrm{mM} \mathrm{KCl}$, 10 ng total DNA, 20 pmol of each forward and reverse primer, $200 \mu \mathrm{M}$ of each dNTPs, and 0.2 units of Taq (Roche Diagnostics, Leiden, The Netherlands). PCR was carried out in the PTC-200 Peltier Thermal Cycler (MJ Research, Waltham, MA, USA) with the following amplification program: $94^{\circ} \mathrm{C}$ for $2 \mathrm{~min}, 13$ cycles of $94^{\circ} \mathrm{C}$ for $30 \mathrm{~s}, 66^{\circ} \mathrm{C}$ for $30 \mathrm{~s}\left(-1^{\circ} \mathrm{C} /\right.$ cycle), and $72^{\circ} \mathrm{C}$ for $30 \mathrm{~s}$; followed by 28 cycles of $94^{\circ} \mathrm{C}$ for $30 \mathrm{~s}, 53^{\circ} \mathrm{C}$ for $30 \mathrm{~s}$, and $72^{\circ} \mathrm{C}$ for $30 \mathrm{~s}$ and an extension cycle of $72^{\circ} \mathrm{C}$ for $7 \mathrm{~min}$. The amplicons were separated on 3\% agarose gels (Roche Diagnostics) in TBE buffer with $0.5 \mu \mathrm{g} /$ $\mathrm{mL}$ ethidium bromide, followed by visualization under a UV transilluminator and estimated using a 20-bp kb molecular marker (Invitrogen, California, USA).

\section{RESULTS AND DISCUSSION}

The development of simple sequence repeat markers, also known as microsatellites, with 2-5 nucleotide repeats for $M$. fijiensis, has recently been undertaken (Yang and Zhong, 2008; Zapater et al, 2008); however, genetic diversity or population structure studies using more robust DNA markers are only at the early stages and more DNA markers are still needed (Molina and Kahl, 2004).

In total, 1528 candidate VNTR loci were identified in the M. fijiensis genome. Many represented imperfect mono-, di- or tri-nucleotide repeats. From this, a set of 42 VNTR markers displaying a larger number of repeat units, as well as repeats with a high level of sequence conservation between the repeat units, were selected for further analyses. Five VNTRs (VNTR_0252_102618, VNTR_1333_7690, VNTR_3786_91361, VNTR_3831_152531, and VNTR_3959_6594) (Table 1), with variable (4-12) repeat units, showed polymorphism in the reference set and were tested on the population that was collected from the aforementioned San Pablo Farm. 
S.A.L. Garcia et al.

2210

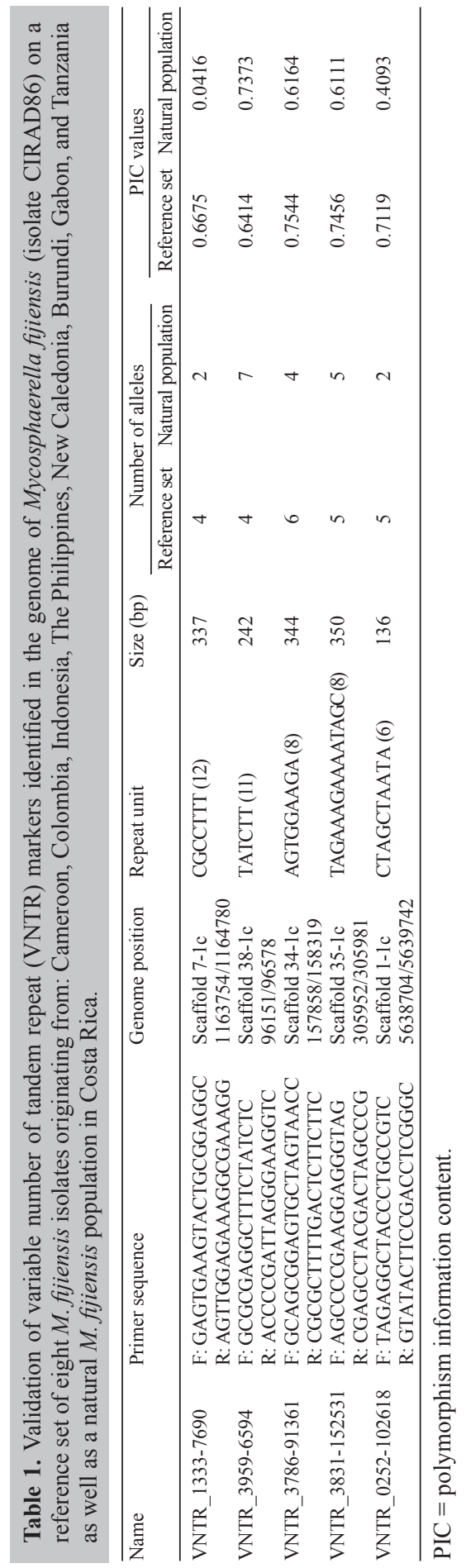

Genetics and Molecular Research 9 (4): 2207-2212 (2010) 
The VNTR primers generated a total of 22 alleles in the $M$. fijiensis reference set and 13 alleles in the San Pablo Farm population set with an average of 4.8 and 4 alleles per locus, respectively. The VNTR primers, which presented the highest number of alleles in the reference set, were VNTR 3786-91361 and VNTRs 3831-152531 and 0252-102618, with 6 and 5 alleles, respectively. In the San Pablo Farm population set, VNTR 3959-6594 and VNTR 3831-152531 presented the highest number of alleles with 7 and 5 alleles, respectively. The polymorphism information content (Botstein et al., 1980) varied from 0.6414 to 0.7544 with an average of 0.7042 for the reference set and from 0.0416 to 0.7373 with an average of 0.4093 for the population set, demonstrating to be highly informative.

Therefore, the versatility of VNTR markers as shown in this report is a great advantage. They are easy to score and can be run on agarose gels, making them an interesting tool, especially for use in less sophisticated laboratories. Rapid population genetic analysis is very important in the air-borne black leaf streak disease, which is a great threat to global banana production and is still occupying new territories. Due to the intensity of fungicide applications, resistance development is a frequently occurring phenomenon; therefore, rapid diagnostics for population analysis are indispensable. The described VNTR markers facilitate such analysis of M. fijiensis populations and support fungicide resistance management and breeding strategies to control banana black leaf streak disease. This is the first report of VNTR-minisatellites for Mycosphaerella fijiensis.

\section{ACKNOWLEDGMENTS}

The authors thank the US Department of Energy - Joint Genome Institute for sequencing the Mycosphaerella fijiensis genome. Ineke de Vries, Odette Mendes and Els Verstappen at Plant Research International B.V., as well as Donny Vargas and Sérgio Durán at CORBANA, for their technical support. Dr. Lute Harm Zwiers, KNAW Fungal Diversity Center, Utrecht, The Netherlands, kindly provided several M. fijiensis reference strains. C.F. Ferreira was supported by a CAPES (http://www.capes.gov.br/) fellowship.

\section{REFERENCES}

Arzanlou M, Abeln EC, Kema GH, Waalwijk C, et al. (2007). Molecular diagnostics for the Sigatoka disease complex of banana. Phytopathology 97: 1112-1118.

Botstein D, White RL, Skolnick M and Davis RW (1980). Construction of a genetic linkage map in man using restriction fragment length polymorphisms. Am. J. Hum. Genet. 32: 314-331.

Buhariwalla HK, Jarret RL, Jayashree B, Crouch JH, et al. (2005). Isolation and characterization of microsatellite markers from Musa balbisiana. Mol. Ecol. Notes 5: 327-330.

Conde L, Waalwijk C, Canto-Canché BB, Kema GHJ, et al. (2007). Isolation and characterization of the mating type locus of Mycosphaerella fijiensis, the causal agent of black leaf streak disease of banana. Mol. Plant Ecol. 8: 111-120.

Cordeiro ZJM, Matos APM, Silva SO, Gasparotto L, et al. (2004). Impact and Management of Black Sigatoka in Brasil. In: XVI Reunião Internacional ACORBAT, Joinville, 63-69. Available at [http://musalit.inibap.org/pdf/IN050658_ en.pdf]. Accessed August 5, 2009.

Creste S, Benatti TR, Orsi MR, Risterucci AM, et al. (2005). Isolation and characterization of microsatellite loci from a commercial cultivar of Musa acuminata. Mol. Ecol. Notes 6: 303-306.

Dsouza M, Larsen N and Overbeek R (1997). Searching for patterns in genomic data. Trends Genet. 13: 497-498.

Lagoda PJ, Noyer JL, Dambier D, Baurens FC, et al. (1998). Sequence tagged microsatellite site (STMS) markers in the Musaceae. Mol. Ecol. 7: 659-663.

Marin DH, Romero RA, Guzmán M and Sutton TB (2003). Black Sigatoka: an increasing threat to banana cultivation. Plant Dis. 87: 208-222.

Molina CM and Kahl G (2004). Genomics of Two Banana Pathogens: Genetic Diversity, Diagnostics, and Phylogeny 
of Mycosphaerella fijiensis and M. musicola. In: Banana Improvement Cellular, Molecular Biology, and Induced Mutations (Jain SM and Swennen RR, eds.). Science Publishers Inc., Enfield, 127-148.

Mourichon X, Carlier J and Fouré E (1997). Sigatoka Leaf Spot Diseases. Musa Disease Fact Sheet No. 8. INIBAP, Montpellier.

Rhodes PL (1964). A new banana disease in Fiji. Commonw. Phytopathol. News 10: 38-41.

Rozen S and Skaletsky H (2000). Primer3 on the WWW for general users and for biologist programmers. Methods Mol. Biol. 132: 365-386.

Yang BJ and Zhong B (2008). Fourteen polymorphic microsatellite markers for the fungal banana pathogen Mycosphaerella fijiensis. Mol. Ecol. Res. 8: 910-912.

Zapater MF, Duchemin M, Dussart JF, Coste D, et al. (2008). Microsatellite markers for the fungal banana pathogens Mycosphaerella fijiensis, Mycosphaerella musicola and Mycosphaerella eumusae. Mol. Ecol. Res. 8: 1121-1125. 